Supplement of Clim. Past, 14, 991-1014, 2018

https://doi.org/10.5194/cp-14-991-2018-supplement

(c) Author(s) 2018. This work is distributed under

the Creative Commons Attribution 4.0 License.

(c) (1)

Supplement of

Paleoceanography and ice sheet variability offshore Wilkes Land, Antarctica - Part 1: Insights from late Oligocene astronomically paced contourite sedimentation

Ariadna Salabarnada et al.

Correspondence to: Ariadna Salabarnada (a.salabarnada@csic.es)

The copyright of individual parts of the supplement might differ from the CC BY 4.0 License. 


\section{S1. Lithostratigraphy}

Site U1356 from 95.4 to 896 mbsf (Cores 11R to 95R) comprises lithostratigraphic Units I to IX described on shipboard during IODP Expedition 318 (Escutia et al., 2011). Here we present a revised and more detailed lithostratigraphic log (Fig. S1) and a schematic facies interpretation (Fig. S2). Facies are interpreted based on a detailed visual description of the cores during a visit to the IODP-Gulf Coast Repository (GCR) following IODP Proceedings methods in Escutia et al. (2011). We aided our interpretations with shipboard magnetic susceptibility data and highresolution digital-images of the cores, both available from http://web.iodp.tamu.edu. In addition, the XRF core scanner data results obtained from the interval between 641.4 and $689.4 \mathrm{mbsf}$, which is the main focus of this paper, have been interpolated to other intervals down-core where sediments are "in situ." The facies interpretation column in Fig. S2 contains information on whether the sediments are deposited "in situ" or are deposited from allochtonous older materials.

Facies are here described briefly from top to bottom (Fig. S1-2). Early and middle Miocene section is recovered between 95.4 and 430.8 mbsf, Cores U1356-11R to U1356-45R. Sediments are comprised by an alternation between glacial laminated green silty clay and interglacial grey clay-rich diatom oozes. In addition, there are some intervals with Mass Transport deposits (i.e., debris flows). Miocene facies are dominated by mix sedimentary processes between turbidites, contourites and hemipelagites and are included within shipboard lithostratigraphic units I and II (Escutia et al., 2011). The Oligocene section is recovered between 430.8 and 895 mbsf, Cores U1356-46R to U1356-95R-3 $83 \mathrm{~cm}$. From 430.8 to $455 \mathrm{mbsf}$, turbidite facies dominate, with an alternation between dark grey claystones with Nereites ichnofacies and green claystones with silt laminae. Silt laminae have scours at the base, with cross lamination and planar laminations. These facies are included in shipboard lithostratigraphic Unit III. From 455 to $575 \mathrm{mbsf}$, sediments mostly comprise debris flow (DF) Facies, characterized by clast-rich/clast-poor contorted and chaotic sediments with a claystone to sandstone matrix. DF deposits exhibit scours at the base. DF events are locally separated by claystones with silt laminations that present cross and/or planar laminations. Shipboard this corresponded with lithostratigraphic Unit IV, which extended from 459.4-593.8 mbsf. The interval from 575 to $785 \mathrm{mbsf}$ (which includes shipboard lithostratigraphic units V, VI and VII) is characterized by an alternation of two facies (F1 and F2). These facies are explained in detail in the main text of the article, and are composed of an alternation of glacial green claystones with thin silt laminae with planar and cross-bedded laminations presenting different traction and suspension structures (F1). These are interbedded with interglacial highly bioturbated, thicker pale-brown, silty-claytones (F2). This 
alternation is disrupted from 710 to 730 mbsf by a MTDs facies (i.e., slupms). From 785 to 879 mbsf (wthin shipboard lithostratrigraphic unit VIII) slump facies prevail. Slump facies consist predominantly of allochthonous stratified and chaotic sediments of similar lithology to F1 and F2. The interval from 879 to 895 corresponds with lithostratigraphic unit IX described on shipboard. This unit comprises sediments from the middle Eocene and the earliest Oligocene consisting of bioturbated purple silty claystones with some laminations. Erosion/non-deposition surfaces are present within this facies. They are intercalated with coarser green micaceous (very shiny) (sandy) silty-claystone. Laminations with ripples and pinstripe and cross-lamination are also observed. This facies are intercalated with MTD facies composed of these same sediments. The interval between 895 and 896 mbsf is within shipboard lithostratigraphic unit $\mathrm{X}$ and is characterized by a lithological change to Eocene green sands Facies. 
Site U1356

IODP Exp. 318

Cores 11-41R
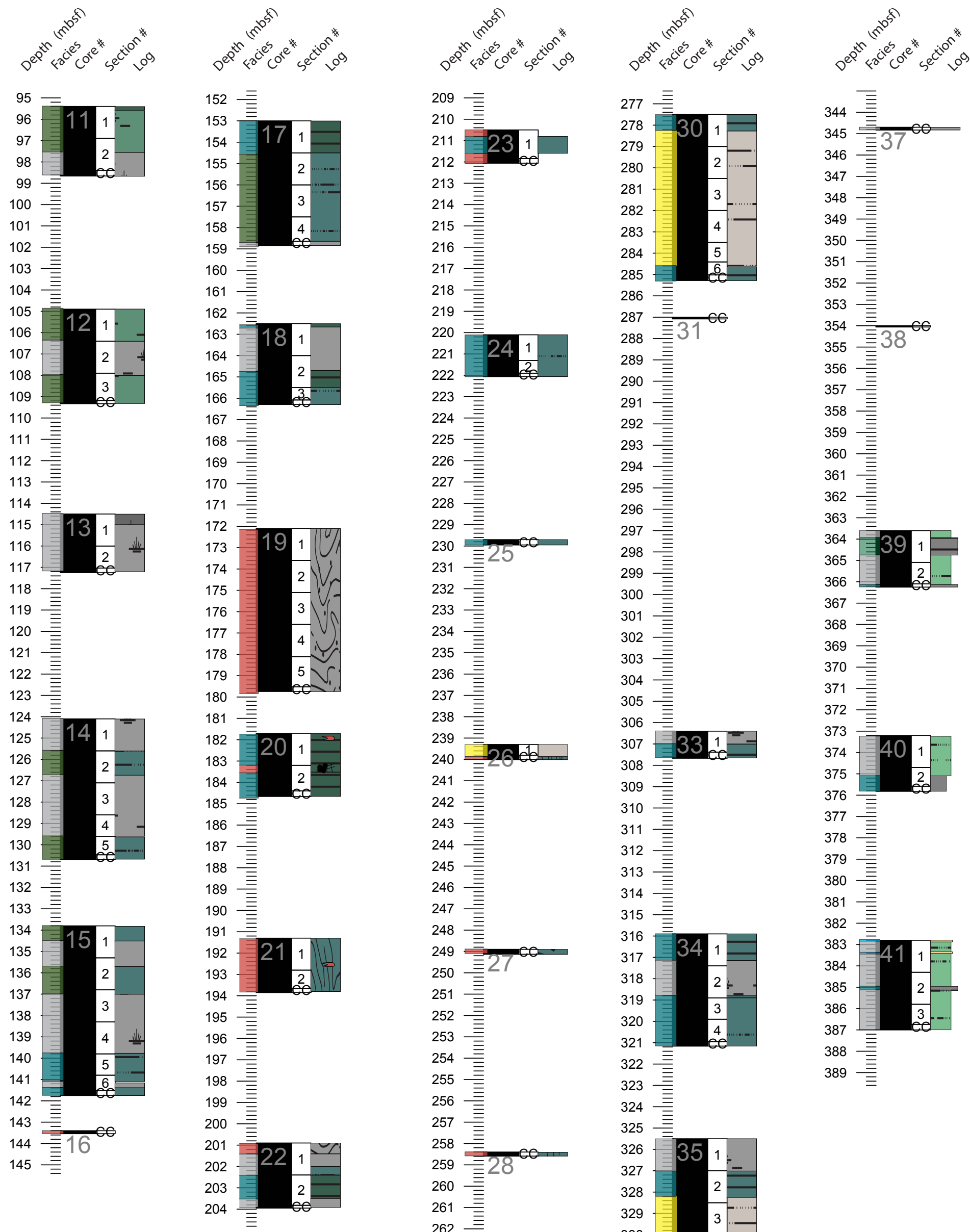

99

156

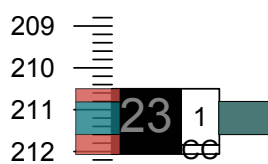

212

213 三

214 产

215 三

$216 \stackrel{\equiv}{ }$

218 三

219 三

220

24

222

223

亨

224 亥

226 亥

227 亥

228 产

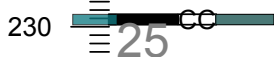

231 三

232 亥

233 亥

234

235

236

238 互

239

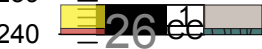

241 三

242 三

243 三

244 言

245 主

247 三

248 三

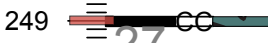

250 豆27

251 三

252 三

253 三

254 三

255 三

256

257 主

259 立28

260 三

261 亥

262 亥

264 亥

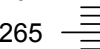

266

267

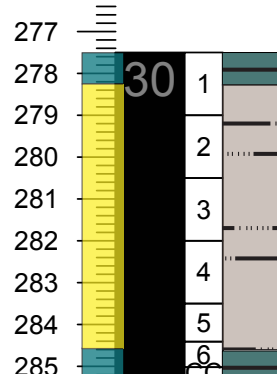

286 三

287 国

288 亥3

289 三

290 产

291 言

292 三

293 三

294 三

295 三

296 三

297 亥

299 三

300 三

301 三

302 三

303 三

304 三

305 亥

$307 \stackrel{\equiv}{\equiv} 331 \bar{E}$

308 三

309 立

310 三

311 三

312 亥

313 立

314 产

316

317

318

319

320

320

322

323 亥

324 三

325

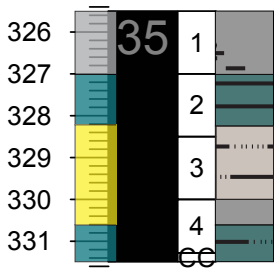

332

333 三

334 三

335 E

336 亥36

337 三

344 亥

345 旁

346 言

347 产

348

350 主

351 三

352 产

353

354 皇38

355 产

356 를

357 틀

358

359

360 产

361 三

362 产

363 言

364

365

366

367

368 三

369 产

370 三

371

372 量

373

374

375

376

377

378

$379 \stackrel{\equiv}{ }$

380 产

381 三

382 三

383

384

385

386

387

388 无

389 三 
Site U1356

IODP Exp. 318

Cores 42-95R

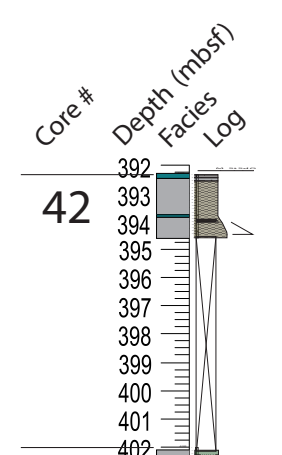

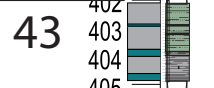

405 目

407 手

408 手

409 录

410 寻

$44^{412}$

413 手

415 手

416 䒜

$417=$

418 彗

$419=$

420

$45 \quad 422=$

423 寻

425 寻

426 寻

427 手

$428=$

430 寻

$46^{431}$

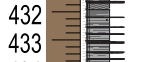

434

$435-\exists$

436 寻

$437=$

438

439 当

$47 \quad 44$

441 政

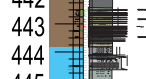

445 非

446 政

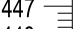

449

$48 \quad 45$

452

452

454 㭋

455 手

456 寻

458

459

$49 \quad 460$ 㭋

462 三

463

464

465 寻

466 寻

467

468 寻

$50470=$

471 目

472

473 龵

475 手

476 手

478 寻

51479

482 师 


\section{LEGEND U1356 CORES 11R-95R}

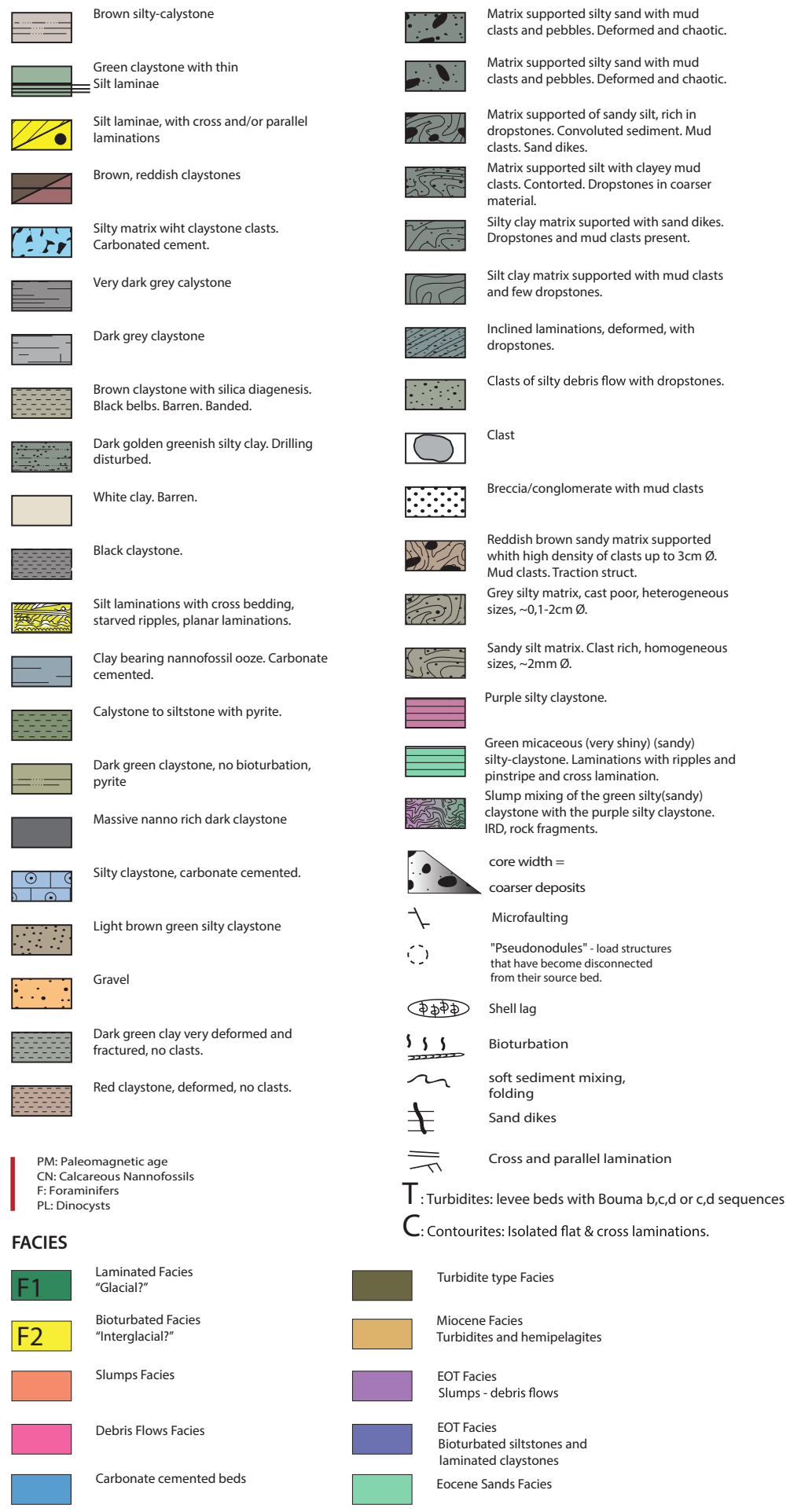

Fig. S1: Detailed sedimentary log from IODP U1356 Site U1356 exp. 318 from 11R to 95R (95.4 to $896 \mathrm{mbsf}$ ). 


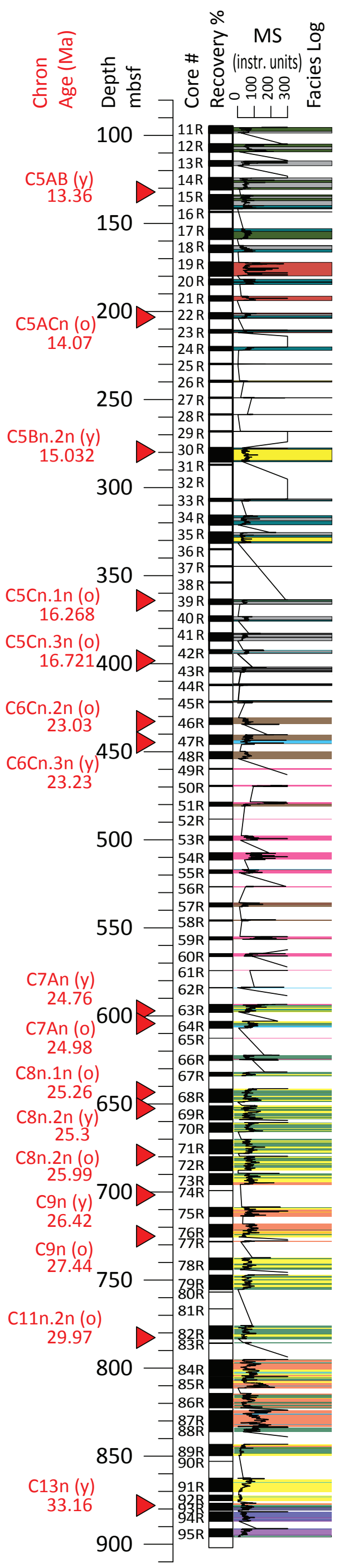

\section{U1356 \\ IODP Exp. 318 \\ Cores 11R-95R \\ Facies Log}

\section{FACIES}

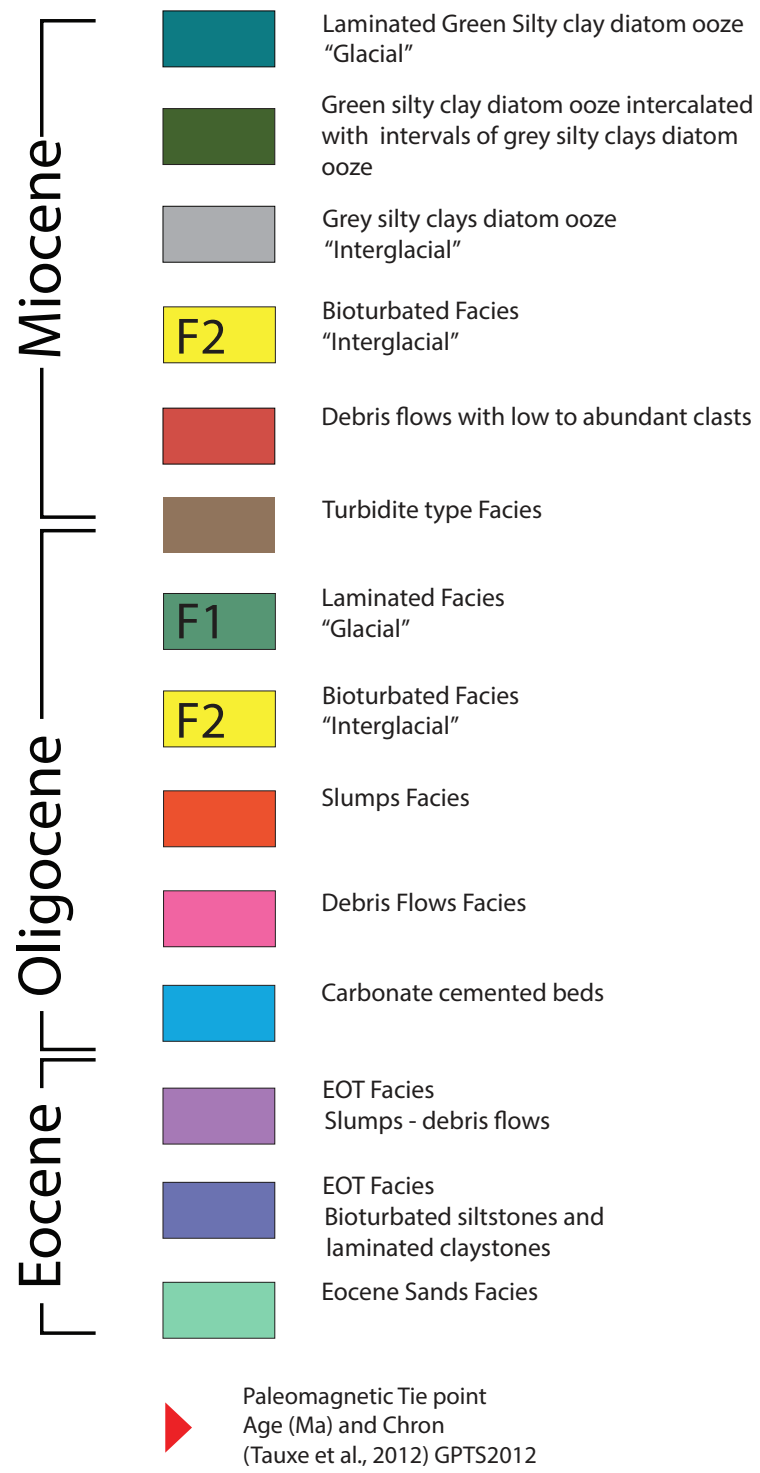

Fig. S2: IODP Site U1356 Exp. 318 from 11R to 95R (95.4 to 896 mbsf). Schematic Facies Log with plotted Magnetic Susceptibility (MS). Paleomagnetic tie points are also present. Ages from Tauxe et al., (2012) are updated to GPTS 2012. 


\section{S.2 Astrochronologic analysis}

\section{Materials and methods}

We followed the procedures published by Meyers et al. (2012) and Wanlu Fu et al. (2016) in order to generate spectral analysis on our data.

We selected $\mathrm{Zr} / \mathrm{Ba}$ ratio as we consider this ratio to integrate and summarize the processes shaping our facies model, showing clearly the marked cyclicity present.

Data preparation:

In order to remove the long-term trend data series were detrended, outliers were removed, and sampling interval was linearly interpolated in order to resample the dataset to an even spacing of $2 \mathrm{~cm}$. Average sedimentation rates between the two paleomagnetic tie end points were linearly interpolated and is $5 \mathrm{~cm} / \mathrm{kyr}$ for the investigated interval. Age model is calibrated to the Geologic Timescale 2012 (GPTS 2012, Table 1).

For initial cyclostratigraphic analyses, we used Anlyseries software (Paillard et al., 1996). We used B-Tukey method in order to preliminary assess the cyclicity on the record on a depth scale. A clear and statistically significant cyclicity is observed in $\mathrm{Ba}, \mathrm{Zr}$ and $\mathrm{Zr} / \mathrm{Ti}$ every $2 \mathrm{~m}(0.5$ cycles $/ \mathrm{m})$, and less significant ones but also reliable at $4.67 \mathrm{~m}(0.21$ cycles $/ \mathrm{m})$, and $1 \mathrm{~m}(0.94$ cycles $/ \mathrm{m})$ (Fig. S3). On the basis of the calculated sedimentation rate, the cycles above $(0.5$ cycles $/ \mathrm{m}$ ) account for $40 \mathrm{Kyr}$. After determining the significant frequency, we filtered the $\mathrm{Zr} / \mathrm{Ba}$ dataset (at depth domain) at 0.5 frequency in order to extract the wavelet and compare it with the obliquity solution for that time-period (Laskar et al., 2004). Cycles can be correlated one to one with a total of 23 cycles of obliquity (Fig. S3). After initial analysis we proceed with Astrochron Evolutive Average Spectral Misfit method (Meyers et al., 2012). Astrochron package is prepared to resolve unevenly sampled series, and changing sedimentation rates.

Time-frequency analysis:

Evolutive Harmonic Analysis (EHA; Fig. S4) of the prepared $\mathrm{Zr} / \mathrm{Ba}$ (in depth scale) data provides an evaluation of changes in the spectral features through depth/time. EHA employs five $3 \pi$ DPSS tapers, and a moving window of $15 \mathrm{~m}$. Significant frequencies are retrieved for further study. 
Astrochronologic testing:

The Evolutive Average Spectral Misfit method (Meyers, 2014) (E-ASM; five $3 \pi$ tapers; searching to the mean Nyquist frequency of 1.504221 cycles $/ \mathrm{m}$ ) was used to test a range of plausible timescales and simultaneously evaluate the reliability of the presence of astronomical cycles. The ETP (eccentricity, obliquity and precession) target periods were determined from La04 (Laskar et al., 2004) using the interval from 25.0 - 26.4 Ma: $400.00 \mathrm{kyr}$ (E1), $131.58 \mathrm{kyr}$ (E2), 99.01 kyr (E3), 40.49 kyr (O1), 32.79 kyr (O2), 20.70 kyr (P1), 19.69 kyr (P2) and 17.06 kyr (P3).

The Zr/Ba MTM Harmonic F-test results of the EHA (Fig. 6) are evaluated using a grid of 100 sedimentation rates spanning $3 \mathrm{~cm} / \mathrm{Kyr}$ to $10 \mathrm{~cm} / \mathrm{Kyr}$. This range of sedimentation rates encompasses the long-term average sedimentation rate for the section based on available paleomagnetic constraints with a total duration of $0.71 \mathrm{Ma}$ and a total stratigraphic thickness between $30-40 \mathrm{~m}$ given the range of plausible correlation horizons for the section. We interpolate an average sedimentation rate of $5 \mathrm{~cm} / \mathrm{Kyr}$.

All spectral peaks above $90 \%$ F-test confidence level were evaluated using E-ASM, and Monte Carlo significance testing utilizing 10,000 simulations. Results with Null Hypothesis Significance Levels (Ho-SL) less than or equal to $0.1 \%$ were identified (Fig. S5).

Astronomical tuning:

Frequency domain minimal tuning (Meyers et al., 2001) is used for tracking obliquity in EHA harmonic F-test for the calibrated periods and sedimentation rates. Spatial frequencies are afterwards converted to sedimentation rates using average period of $41 \mathrm{Kyr}$ (Fig. S6) and a time-space map is created with a new calibrated time series. Time series is afterwards anchored to our paleomagnetic tie points (Fig. S7).

MTM and EHA results on the tuned data provide further evidence of the presence of precession, obliquity and eccentricity cycles, supporting the obliquity tuning (Fig. S8).

Significant Harmonic F-test peaks that achieve 95\% CL are: $102.77 \mathrm{Kyr}, 69.26 \mathrm{Kyr}, 40.84 \mathrm{Kyr}$, $30.05 \mathrm{Kyr}, 22.27 \mathrm{Kyr}, 20.68 \mathrm{Kyr}$ (Fig. S8).

The new time-scale is used to tune the other records $(\mathrm{Zr} / \mathrm{Ti}$; $\mathrm{Ca} / \mathrm{Ti} ; \mathrm{MS} ; \mathrm{Ba})$. EHA is then applied to tuned records in order to see the frequencies that appear (Fig. S9). 
Orbital frequencies were tested in each core section individually in the $\mathrm{Zr} / \mathrm{Ba}$ dataset in the depth scale in order to assure that cyclicity is not an artefact related to the gaps in the series (Fig. S10).

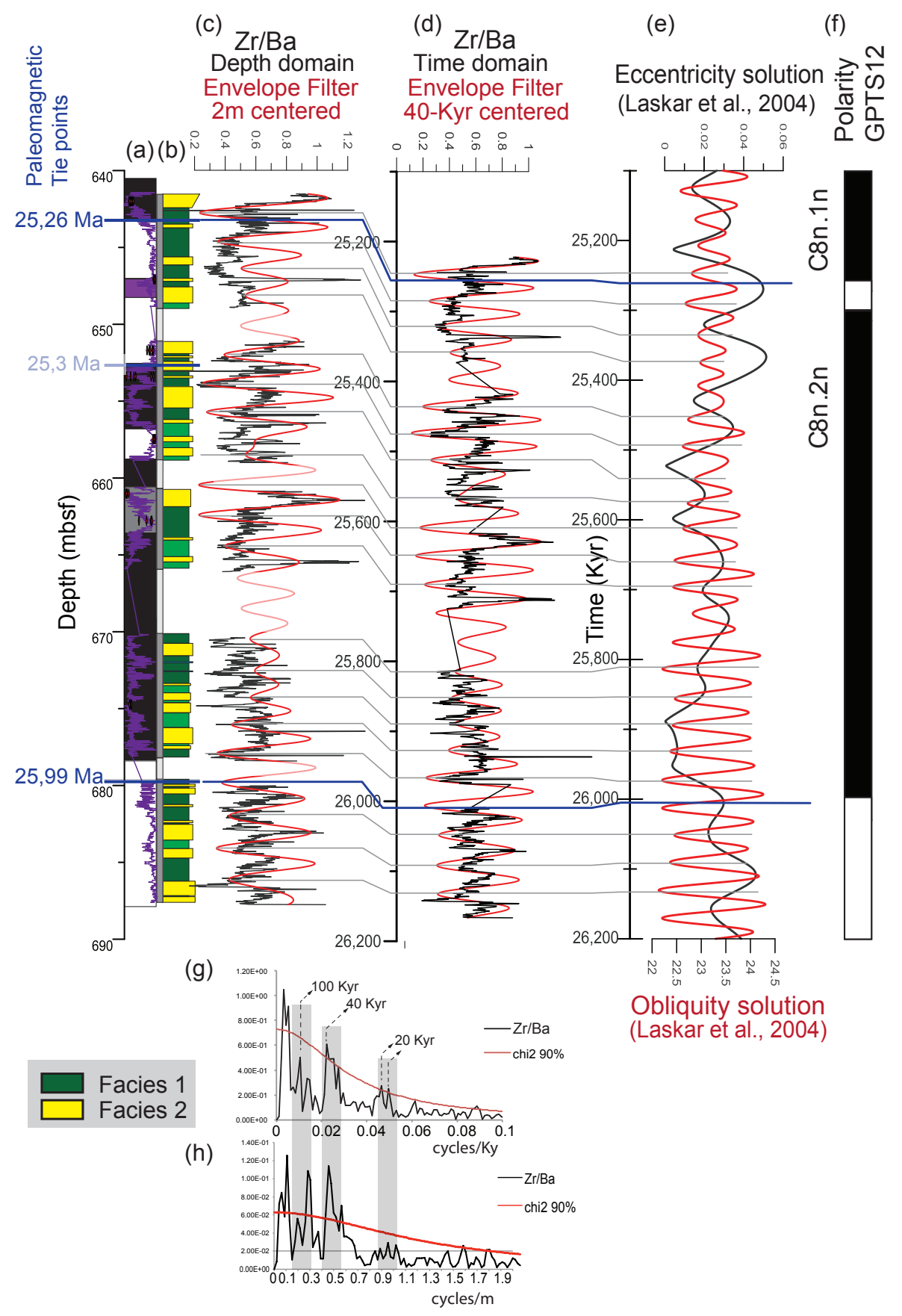

Fig. S3: Tuning of $\mathrm{Zr} / \mathrm{Ba}$ to the obliquity solution. $\mathrm{Zr} / \mathrm{Ba}$ (in the depth domain) is tuned to the obliquity solution cycle by cycle. Tuning of $\mathrm{Zr} / \mathrm{Ba}$ record (in depth scale) and bandpass filtering were done in Analyseries (Paillard et al., 1996). (a) Magnetostratigraphic chrons (Tauxe et al., 2012); (b) schematic stratigraphic log; (c) $\mathrm{Zr} / \mathrm{Ba}$ data in depth scale with the envelope filter centred at $2 \mathrm{~m}$ (in red); (d) $\mathrm{Zr} / \mathrm{Ba}$ data in time scale using paleomagnetic tie points and a linear sedimentation rate, with the envelope filter centred at $40 \mathrm{Kyr}$ (in red); (e) Eccentricity and obliquity solutions (Laskar et al., 2004); (f) Polarity chrons from the GPTS2012; (g) Blakmann-Tukey in the $\mathrm{Zr} / \mathrm{Ba}$ data in time domain (not tuned), with statistical (>90\%) periodic peaks in the $40 \mathrm{Kyr}$ and $20 \mathrm{Kyr}$ periodicities; g) Blakmann-Tukey in the $\mathrm{Zr} / \mathrm{Ba}$ data in depth domain, with statistical ( $>90 \%)$ periodic peaks. 


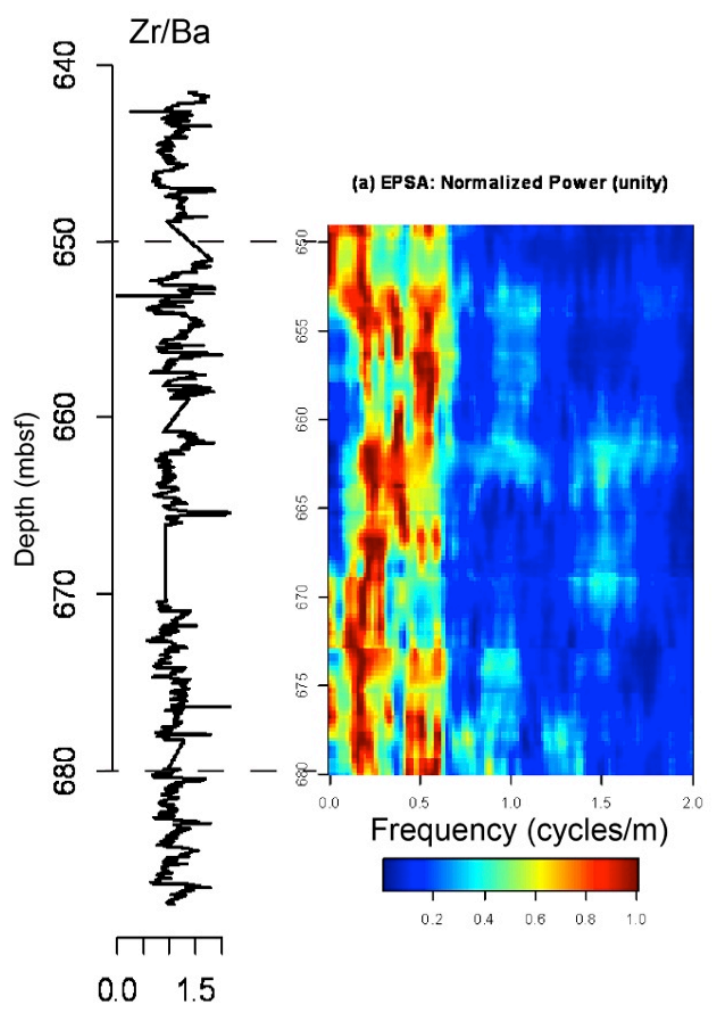

Fig. S4: Evolutive Harmonic Analysis (EHA) in depth scale $\mathrm{Zr} / \mathrm{Ba}$ data. The detrended $\mathrm{Zr} / \mathrm{Ba}$ data is linearly interpolated to a constant sample spacing of $2 \mathrm{~cm}$ prior to analysis. EHA employs with 3DSDP tapers and a 15 window. 
(a)

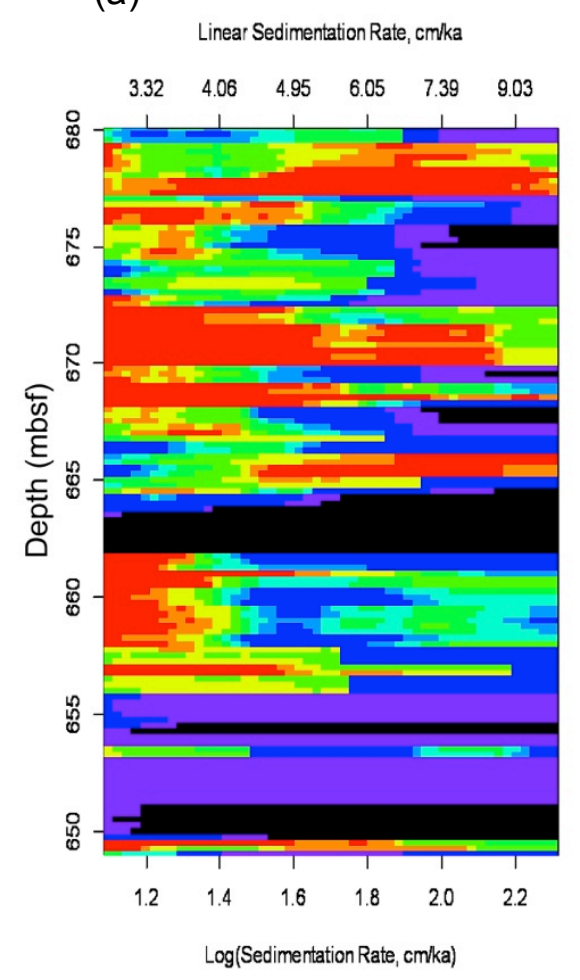

(b)

Ho-SL $\%$

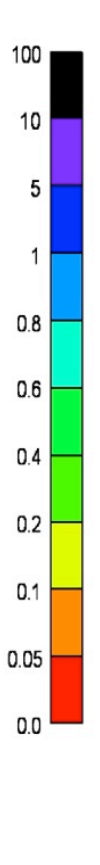

(c)

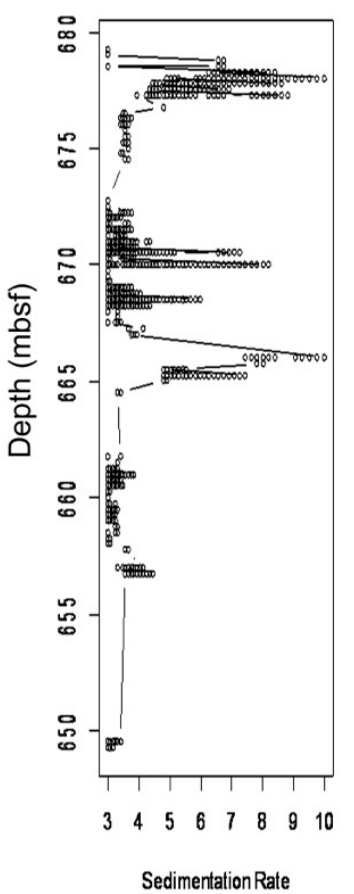

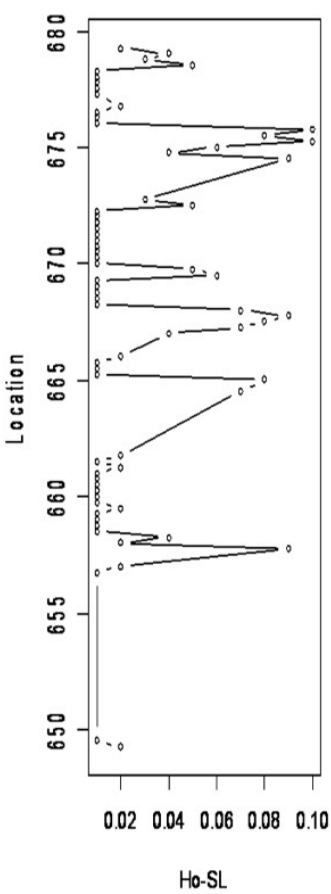

Fig. S5: Astrochronologic testing using evolutive ASM analysis. (a) Evolutive ASM plot, displaying Ho-SL values (90\% confidence level), across sedimentation rates spanning 3 to 10 cm/kyr. (b-c) Summary of evolutive ASM results, using a threshold Ho-SL value of 0.1 to identify optimal sedimentation rates. (b) displays each sedimentation rate, and (c) displays the associated Ho-SL. 


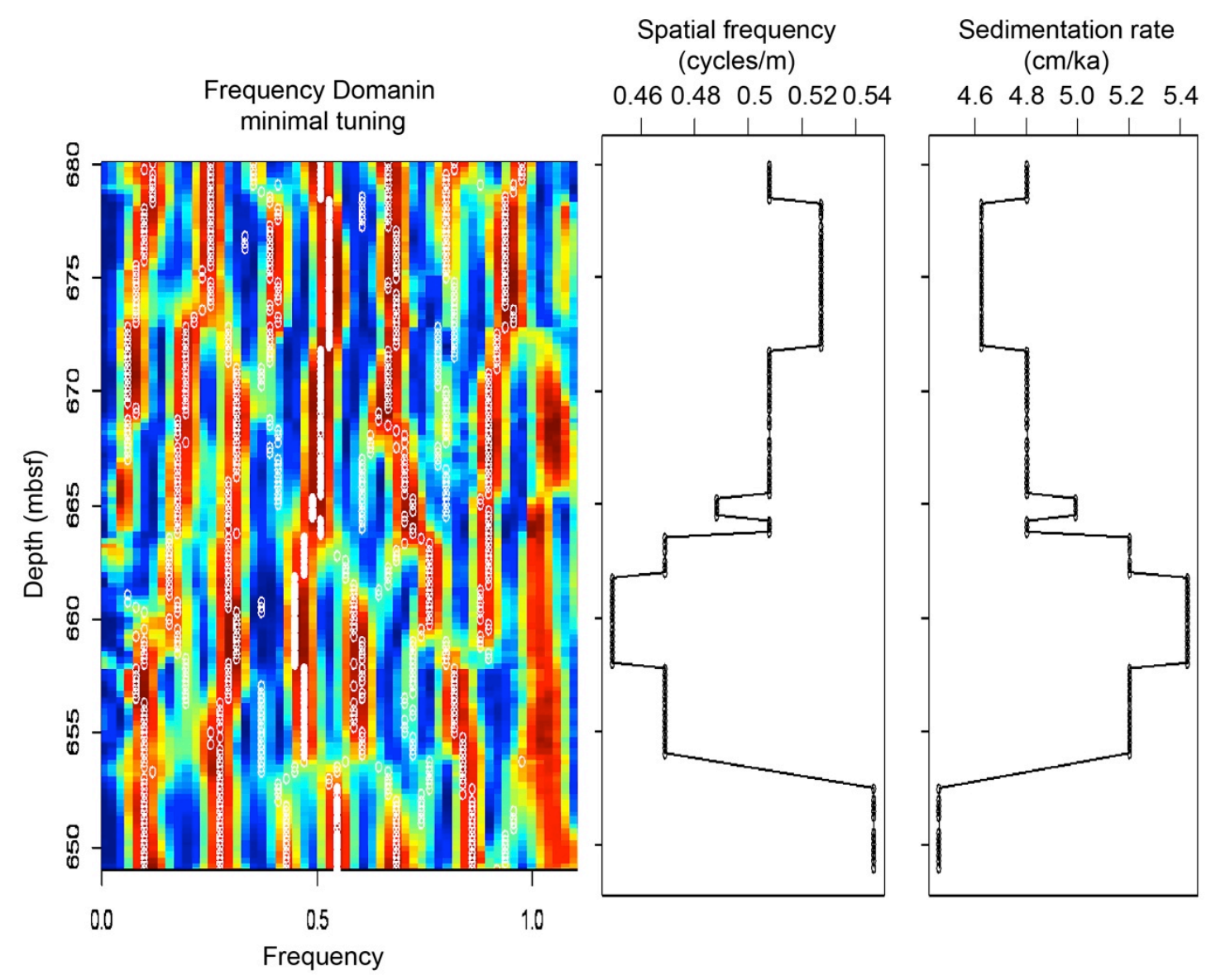

Fig. S6: Frequency tracking for minimal tuning. The obliquity cyclicity $(41 \mathrm{Kyr})$ can be tracked in the EHA harmonic F-test confidence level results by setting the fmin $=0.01$ and $f \max =0.4$ based on the spatial frequencies calculated by EASM results. Calculated sedimentation rates based on spatial frequency tracking. 
$\mathrm{Zr} / \mathrm{Ba}$

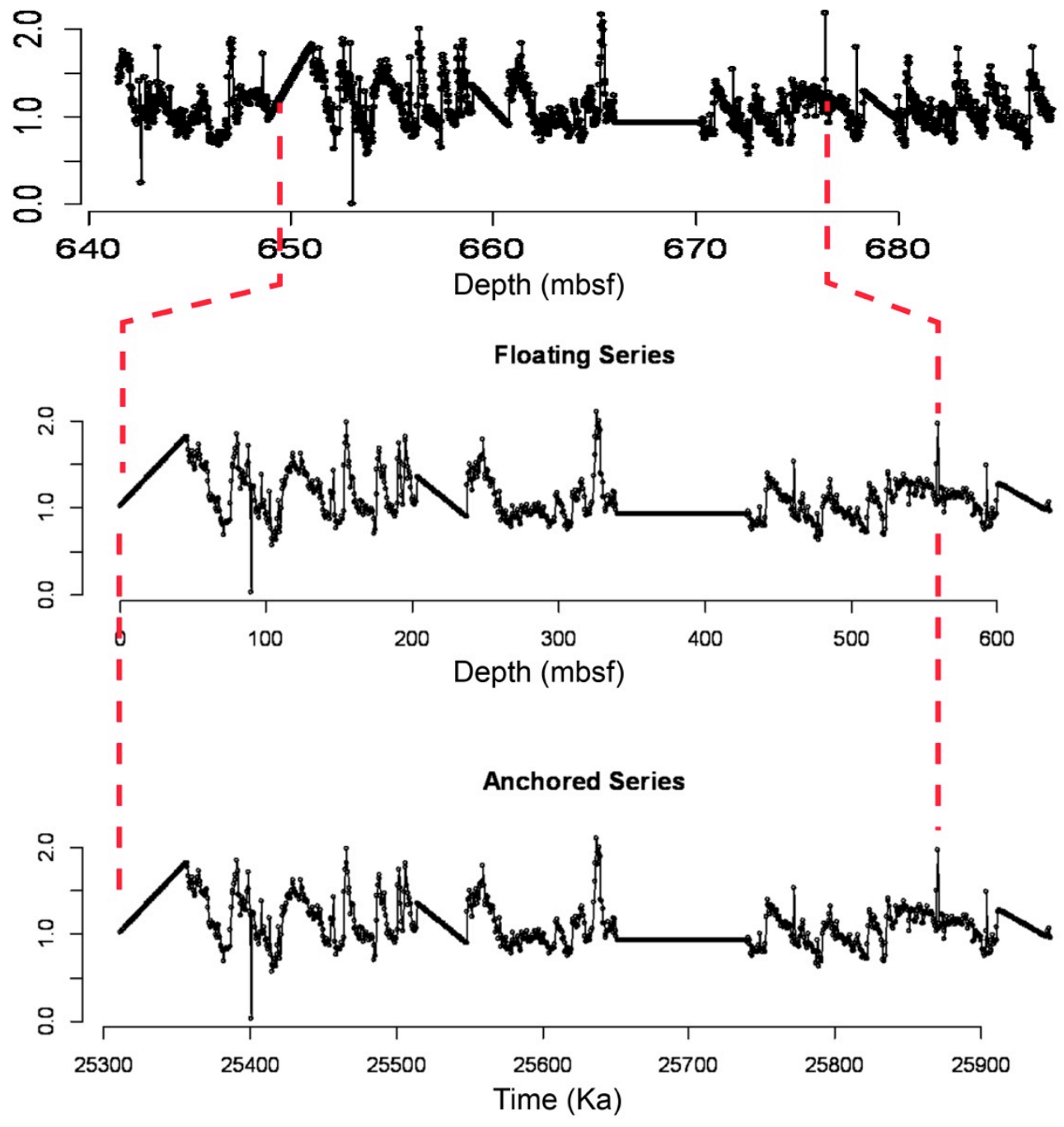

Time-space map

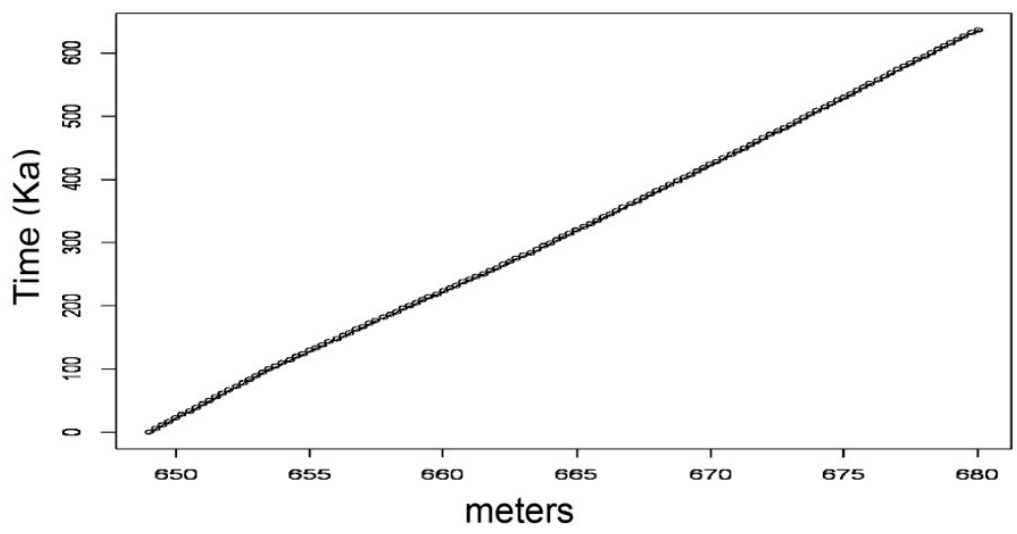

Fig. S7: Tuned record and depth-time plot derived by frequency domain minimal tuning to the obliquity cycle. The red dotted lines show the correlated depth and time. 

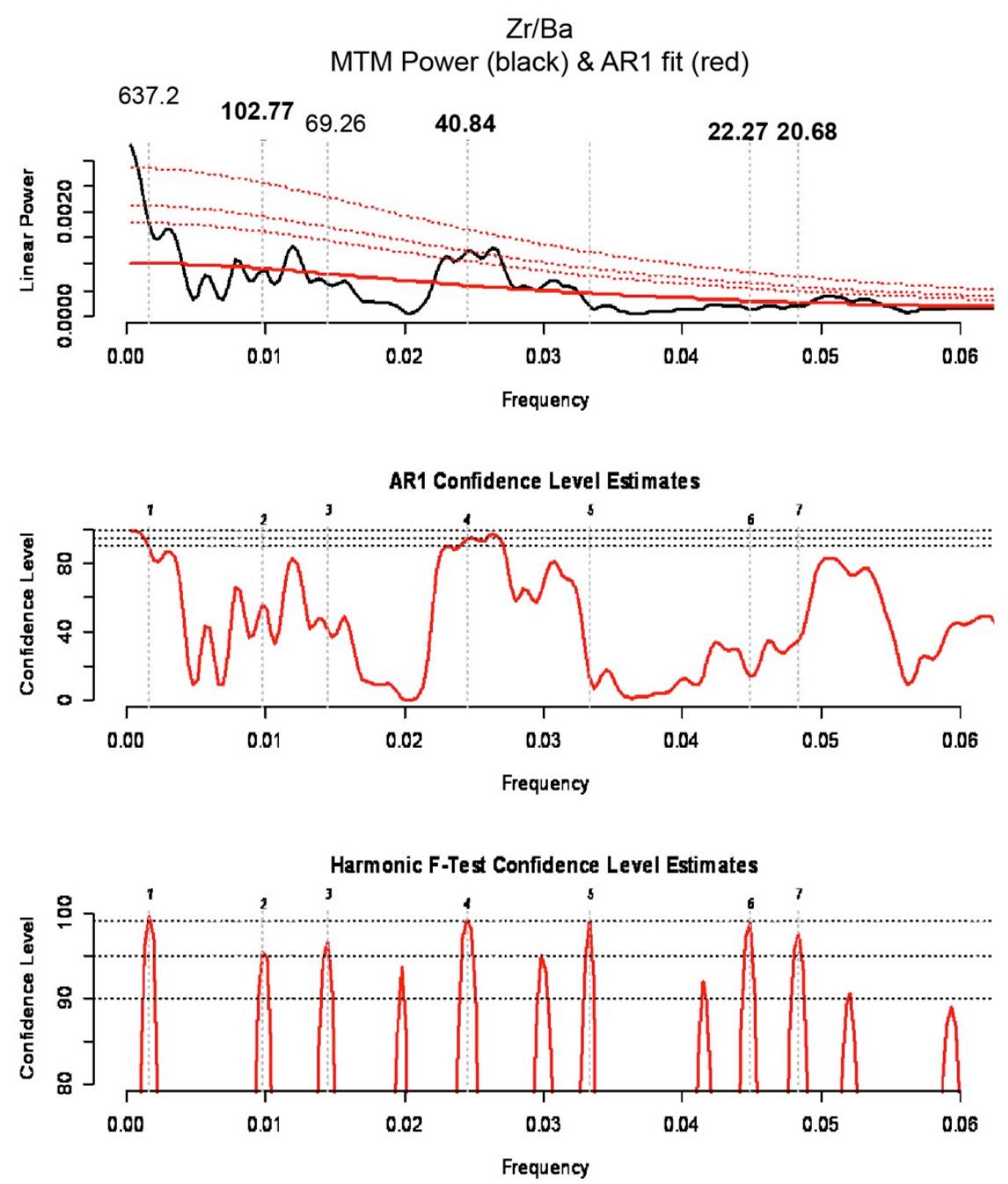

Fig. S8: MTM results of the tuned data with the major periods in kyr. These peaks achieve the 95\% confidence level for both the MTM harmonic F-test and the AR1 red noise model or the AR1 noise model only. 
$\mathrm{Zr} / \mathrm{Ba}$ Tuned

EHA with 300win

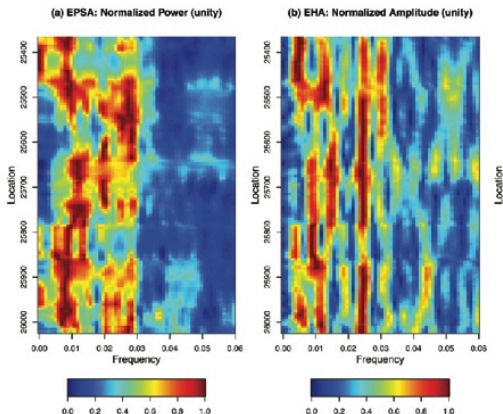

$\mathrm{Zr} / \mathrm{Ti}$ Tuned

EHA with 300win
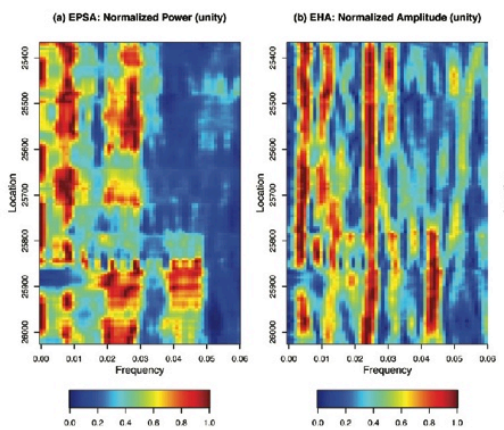

$\mathrm{Ca} / \mathrm{Ti}$ Tuned

EHA with 300win
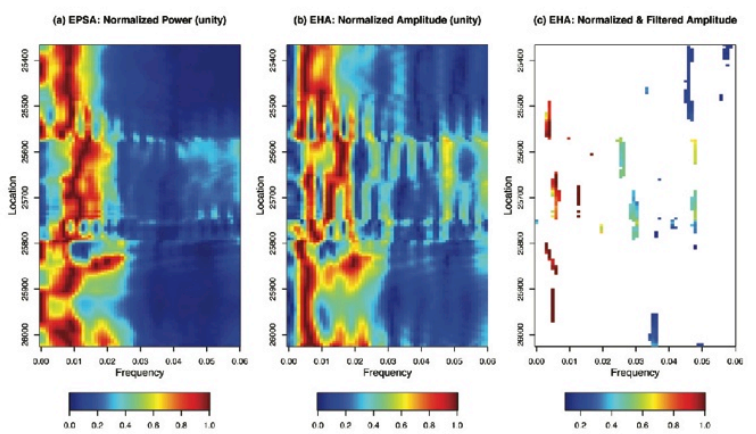

MS Tuned

EHA with 300win
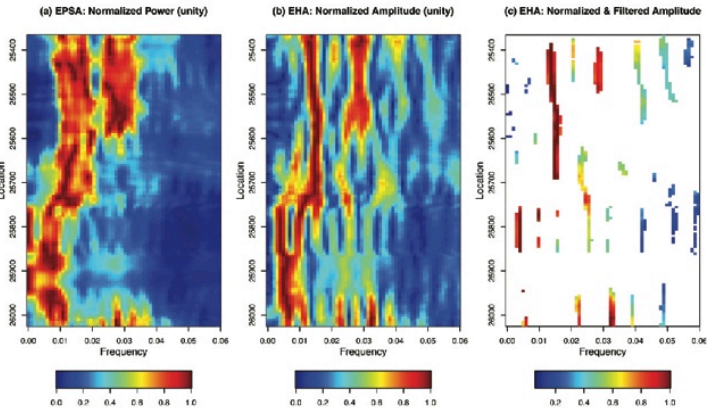

Ba Tuned

EHA with 300win
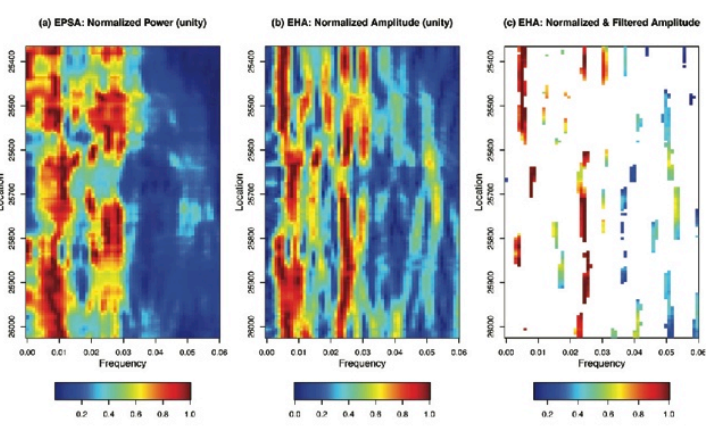

\section{ETP Solution EHA with 200win}
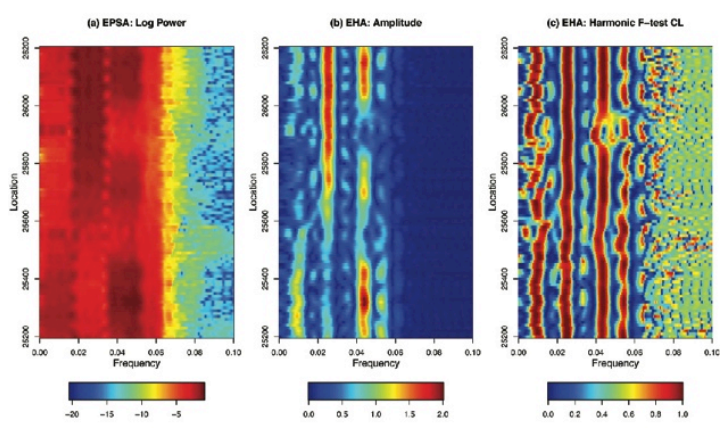

Fig. S9: Following $\mathrm{Zr} / \mathrm{Ba}$ tuning (a), MS (b), $\mathrm{Zr} / \mathrm{Ti}$ (c), $\mathrm{Ba}(\mathrm{d})$, and $\mathrm{Ca} / \mathrm{Ti}$ (e) have been tuned. EHA analysis was applied in order to depict the frequencies. EHA on the ETP solution is also added in order to compare the resulting frequencies (f). 


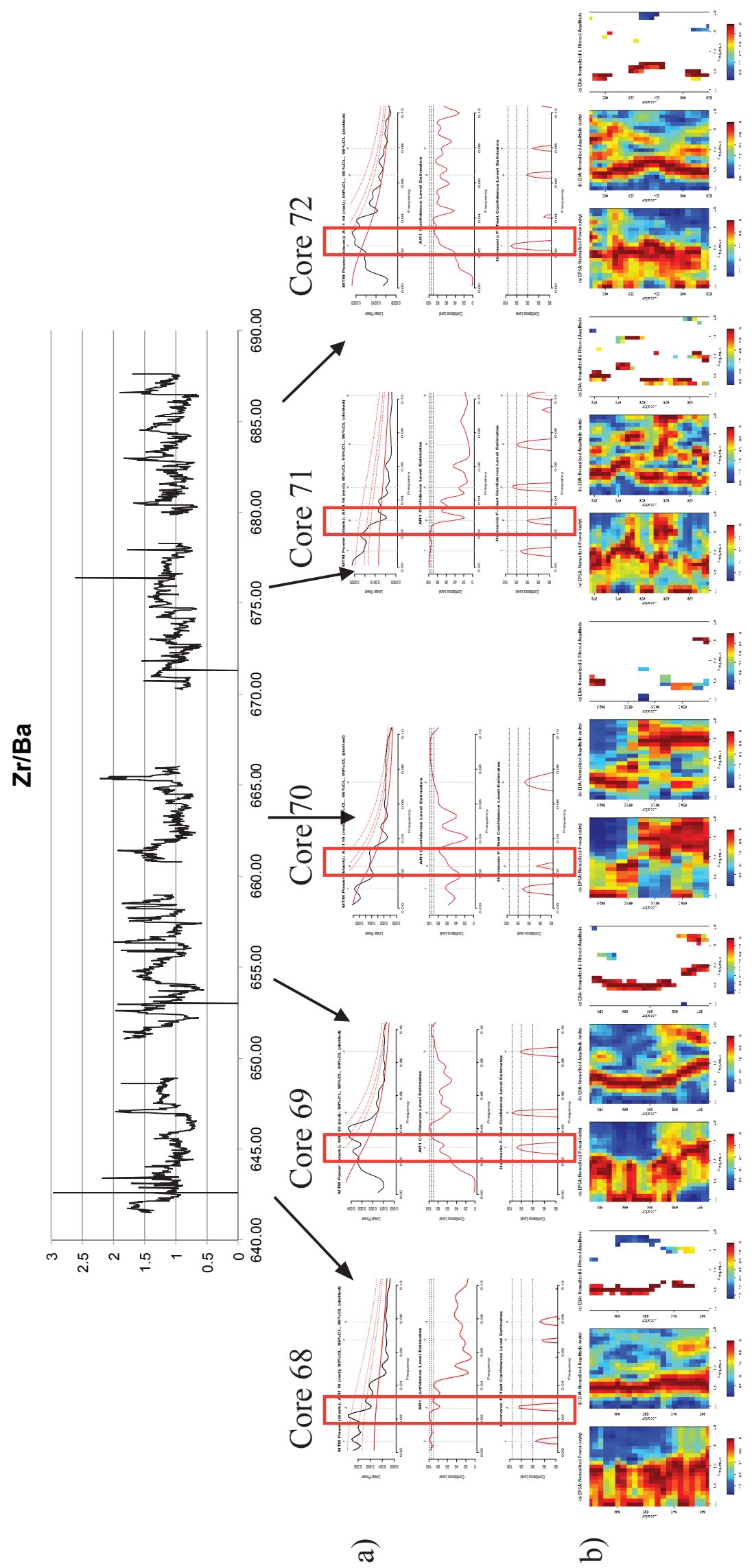

Fig. S10: Spectral analysis over individual core sections for the $\mathrm{Zr} / \mathrm{Ba}$ dataset on the depth scale. The 0.5 cycle $/ \mathrm{m}$ (that counts for obliquity) achieve $>90 \%$ significance in all cores except for core 70 where smaller frequencies seem to dominate. Changes in peak frequency seem to be dominated by slightly changes in sedimentation rate. Each core was analysed by a) MTM and b) EHA with a $5 \mathrm{~m}$ window. 


\section{R_analysis}

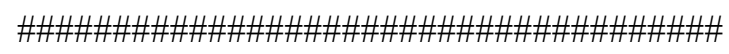

\# (1) LOAD THE R-PACKAGE 'ASTROCHRON'

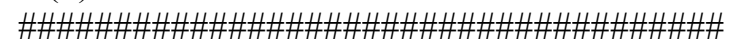

library(astrochron)

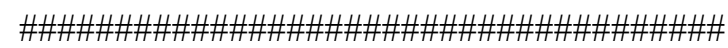

\# (2) READ DATA FILE

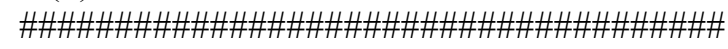

\# Read the carbon isotope data from file 'CarbonIso.csv'

dat $<-\operatorname{read}(\mathrm{d}=0)$

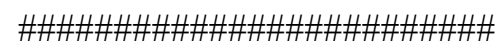

\# (3) PREPARE TIME SERIES

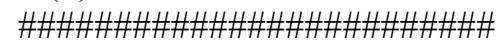

\# The median sampling interval of the prepared data is $0.02 \mathrm{~m}$, and the mean

sampling interval is $0.023 \mathrm{~m}$

\# Resample $\mathrm{Zr} / \mathrm{Ba}$ data to $2.5 \mathrm{~cm}$ sampling grid, using piecewise linear

interpolation

$\mathrm{ZrBa}<-$ linterp(dat, $\mathrm{dt}=0.025)$

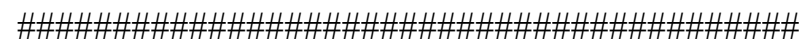

\# (4) PERFORM EVOLUTIVE HARMONIC ANALYSIS

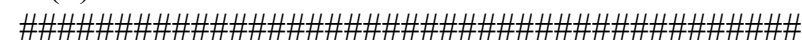

$\operatorname{mtmML} 96(\mathrm{ZrBa}, \mathrm{xmax}=2, \mathrm{pl}=2$, siglevel $=.90, \operatorname{sigID}=\mathrm{T})$

$\operatorname{mtm}(\mathrm{ZrBa}, \mathrm{xmax}=2, \mathrm{pl}=2$, $\operatorname{sigID}=\mathrm{T})$

\# Use a 12 meter window, with five 3pi DPSS tapers.

\#* Search up to the mean Nyquist frequency of $1.504221 \mathrm{cycle} / \mathrm{m}$

\#* Output F-test confidence level estimates for evolutive average spectral misfit (ASM) analysis.

$\operatorname{prob}=\mathrm{eha}(\mathrm{ZrBa}, \mathrm{fmax}=2$, output $=4$, genplot $=4, \mathrm{pl}=2, \mathrm{ydir}=-1$, win $=15)$

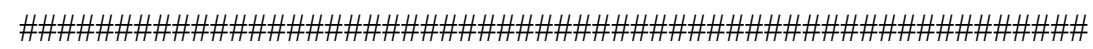

\# (5) IDENTIFY TARGET PERIODS FOR AVERAGE SPECTRAL MISFIT ANALYSIS

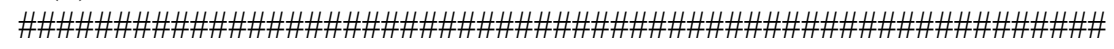

\# Obliquity and precession terms from Laskar et al. (2004)

model $=$ etp $(\operatorname{tmin}=25000, \operatorname{tmax}=26400)$

eha( model, win $=200$, fmax $=0.1$, sigID $=\mathrm{T}, \mathrm{pad}=10000)$

$\operatorname{mtm}(\operatorname{model}, \mathrm{xmax}=0.1, \mathrm{pl}=2, \operatorname{sig} I \mathrm{D}=\mathrm{T})$

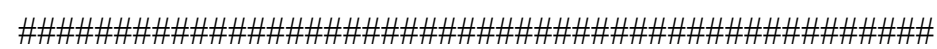

\# (6) EVOLUTIVE AVERAGE SPECTRAL MISFIT ANALYSIS

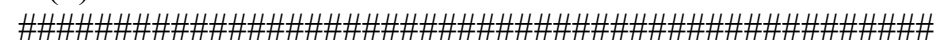

\# Set up analysis parameters:

\#* Astronomical target frequencies are determined from Laskar et al. (2004)

target $=\mathrm{c}(1 / 404,1 / 124,1 / 95,1 / 54,1 / 41,1 / 29,1 / 23,1 / 19)$

\#Ray $=\left(1 / \mathrm{N}^{*} \mathrm{Ax}\right)$ on $\mathrm{N}=$ number of points in data series and $\mathrm{Ax}=$ sampling resolution of data series

\# * Use average sampling interval to estimate the Nyquist frequency (for $1 /(0.025 \mathrm{~m}$ sampling *

2) Fnyq $=(1 / 2 * A x)$

rayleigh $=0.0217$

nyquist $=20$

\#* Average sedimentation rates is around $5 \mathrm{~cm} / \mathrm{Kyr}$

\# The total duration between the youngest and oldest age is $0.71 \mathrm{Ma}+/-$ ? Ma. 
\# Given the range of plauisble correlation horizons into the LO section,

\# the total stratigraphic thickness can range from $30 \mathrm{~m}$ to $40 \mathrm{~m}$.

\# Execute evolutive ASM analysis. This will take 10-20 minutes to complete.

res $1=$ eAsm (prob,target=target,rayleigh=rayleigh, nyquist $=$ nyquist, , $=d m i n=3$, sedmax $=10$, numsed

$=100$, siglevel $=0.95$, iter $=10000$, output $=4$ )

\# Track Ho-SL minima from evolutive ASM results

\#* Identify those results with Ho-SL less than or equal to $0.1 \%$

$\operatorname{pl}(1)$; eAsmTrack(res1[1],threshold=0.1,ydir $=1$ )

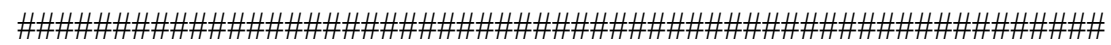

\# (7) EXAMINE SELECTED SPECTRA AND ASM-CALIBRATED PERIODS

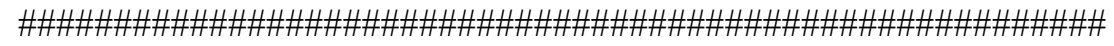

\# F-test CL spectrum from $43.965 \mathrm{~m}$

\# Calculate calibrated periods in kyr (observed)

prob_674.53=extract(prob,get $=674.53)$

1/(peak(prob_674.53,level=0.9)[2]*0.025)

prob_670.03 $=$ extract $($ prob,get $=670.03)$

$1 /\left(\right.$ peak $($ prob_670.03,level $\left.=0.9)[2]^{*} 0.025\right)$

prob $656.03=$ extract $($ prob,get $=656.03)$

$1 /\left(\right.$ peak $($ prob_656.03,level $\left.=0.9)[2]^{*} 0.025\right)$

prob_661.03 $=$ extract $($ prob,get $=661.03)$

$1 /($ peak $($ prob_661.03,level $=0.9)[2] * 0.025)$

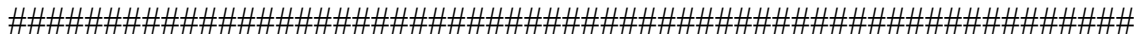

\# (8) ASTRONOMICALLY-TUNE Zr/Ba DATA USING

\# FREQUENCY-DOMAIN MINIMAL TUNING (Meyers et al., 2001)

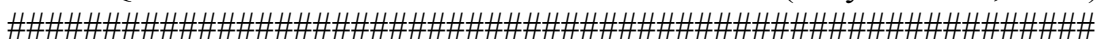

\# Track obliquity in EHA harmonic F-test confidence level given the ASM-calibrated periods

\# Track obl term on the basis of the ASM calibrated sedmentation rates

\# Note that the Rayleigh frequency is 0.0217 cycles $/ \mathrm{m}$

freqs $=$ trackFreq $($ prob $, \mathrm{fmin}=0.023, \mathrm{fmax}=1$, threshold $=0.9)$

\# convert spatial frequencies to sedimentation rates using average period of $41 \mathrm{kyr}$

sedrate $=$ freq2sedrate $($ freqs,period $=41, \mathrm{ydir}=-1)$

sedrate

\# View the calibrated sedimentation rates on depth sedrate

\# Integrate the sedimentation rate curve to create a time-space map

time $=$ sedrate2time(sedrate)

\# View the calibrated time series

time

\# The duration of specific interval can be calculated by the output of sedrate and time

\# Tune the ZRBA series using the time-space map

tuned $=$ tune $(\mathrm{ZrBa}$,time $)$

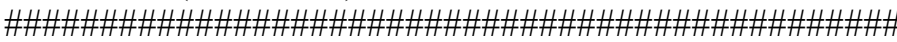

\# (9) PREPARE TUNED SERIES AND EVALUATE SPECTRA

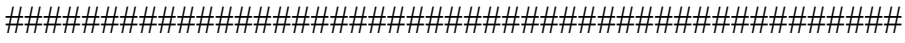

\# Interpolate the tuned series. Median sampling interval is $0.5 \mathrm{kyr}$ and mean is $0.55 \mathrm{kyr}$.

\# Will use AR1 test; use a conservative interpolation to avoid introducing serial correlation.

datatuned $=\operatorname{linterp}($ tuned, $\mathrm{dt}=0.6$ )

\# Perform MTM analysis on the tuned series

$\mathrm{spec}=\mathrm{mtm}($ datatuned $, \mathrm{tbw}=2, \mathrm{pl}=2$, siglevel $=0.95, \mathrm{xmax}=0.06$, output $=1, \operatorname{sigID}=\mathrm{T})$ 
\# identify periods of AR1 CL peaks that acheive the $90 \%$ AR1 CL

$1 /$ peak $(\operatorname{cb}(\operatorname{spec}, \mathrm{c}(1,4))$,level $=95)[2]$

\# Perform EHA on the tuned series

$\mathrm{ZrBa}$-final $<-\operatorname{read}(\mathrm{d}=0)$

pwr $=$ eha $($ datatuned, $f \max =0.06$, output $=2, \mathrm{ydir}=-1$, win $=250$ )

plotEha(pwr,pl=1,ydir=-1)

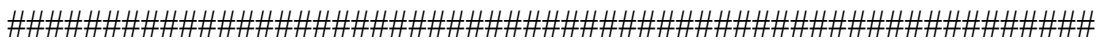

\# (10) BANDPASS FILTERING AND ECCENTRICITY AMPLITUDE

MODULATION ANALYSIS

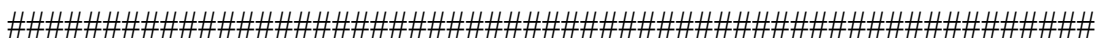

\# Perform bandpass-filtering on the tuned series to extract short eccentricity (E2+E3)

e23_data $=$ bandpass (datatuned,flow $=0.006$, fhigh $=0.011, \mathrm{xmax}=0.02$ )

\# Perform bandpass-filtering on the eccentricity terms from Laskar et al. (2011)

model=getLaskar("la10d")

model $=$ iso $($ model $, \mathrm{xmin}=25000, \mathrm{xmax}=26400)$

e23_model $=$ bandpass $($ model,flow $=0.006$,fhigh $=0.011, x \max =0.02)$ \#short-term

eccentricity

\# Evaluate the alignment between the amplitude envelope of the filtered short-term eccentricity and the filtered long-term eccentricity

am_data $=$ hilbert(bandpass(datatuned,flow $=0.006$, fhigh $=0.011)$ )

$\operatorname{pl}(\overline{1})$

plot(s(am_data),type="1",ylim=c(-3,3))

lines(s(e1_data),col="red")

\#Anchor the tuned data to a tie point from the time scale where 606.226 is equivalent to 678.78

$\mathrm{ZrBa}$ _tuned2=anchorTime(datatuned,606.2262,25990,flipOut=T,timeDir=2)

write.csv $(\mathrm{ZrBa}$ _tuned2,file="ZrBa_tuned_at_606.226to25990.csv") \#Save data

Tune other data series and analyse with EHA:

$\mathrm{Ba}<-\operatorname{read}(\mathrm{d}=0)$

Ba tuned $=$ tune $(B a$, time $)$

eha(linterp(Ba_tuned,dt $=0.5), \mathrm{fmax}=0.06$,output $=2, \mathrm{ydir}=-1$, win $=150$ )

Ba_tuned=anchorTime(datatuned,678.9,25990,flipOut=T,timeDir=2)

$\mathrm{MS}<-\operatorname{read}(\mathrm{d}=0)$

MS_tuned $=$ tune $(\mathrm{MS}$, time)

eha(linterp(MS_tuned, $\mathrm{dt}=0.5), \mathrm{fmax}=0.06$, output $=2, \mathrm{ydir}=-1, \mathrm{win}=150$ )

MS_tuned=anchorTime(datatuned,678.9,25990,flipOut=T,timeDir=2) 


\section{References:}

Escutia, C., Brinkhuis, H., Klaus, A., Scientists, I.E. 318, 2011. Expedition 318 summary, in: Proceedings of the Integrated Ocean Drilling Program, Volume 318.

Fu, W., Jiang, D., Montañez, I.P., Meyers, S.R., Motani, R., Tintori, A., 2016. Eccentricity and obliquity paced carbon cycling in the Early Triassic and implications for post-extinction ecosystem recovery. Sci. Rep. 6, 27793.

Laskar, J., Robutel, P., Joutel, F., Gastineau, M., Correia, a. C.M., Levrard, B., 2004. A longterm numerical solution for the insolation quantities of the Earth. Astron. Astrophys. 428, 261-285.

Meyers, S.R., Sageman, B.B., Hinnov, L.A., 2001. Integrated quantitative stratigraphy of the Cenomanian-Turonian Bridge Creek Limestone Member using evolutive harmonic analysis and stratigraphic modeling. J. Sediment. Res. 71, 628-644.

Meyers, S.R., Sageman, B.B., Arthur, M.A., 2012. Obliquity forcing of organic matter accumulation during Oceanic Anoxic Event 2. Paleoceanography 27.

Paillard, D., Labeyrie, L., Yiou, P., 1996. Macintosh Program performs time-series analysis. Eos, Trans. Am. Geophys. Union 77, 379-379.

Tauxe, L., Stickley, C.E., Sugisaki, S., Bijl, P.K., Bohaty, S.M., Brinkhuis, H., Escutia, C., Flores, J. a., Houben, a. J.P., Iwai, M., Jiménez-Espejo, F., McKay, R., Passchier, S., Pross, J., Riesselman, C.R., Röhl, U., Sangiorgi, F., Welsh, K., Klaus, A., Fehr, A., Bendle, J. a. P., Dunbar, R., González, J., Hayden, T., Katsuki, K., Olney, M.P., Pekar, S.F., Shrivastava, P.K., van de Flierdt, T., Williams, T., Yamane, M., 2012.

Chronostratigraphic framework for the IODP Expedition 318 cores from the Wilkes Land Margin: Constraints for paleoceanographic reconstruction. Paleoceanography 27, 19. 